\title{
Internality, Controllability, and the Effectiveness of Attributional Interpretations in Counseling
}

\author{
Nancy L. Forsyth and Donelson R. Forsyth \\ Virginia Commonwealth University
}

\begin{abstract}
An attributional approach to counseling was investigated in two separate studies. In Experiment 1 the theoretical basis for the use of attributional interpretations was tested by giving individuals who had just received a negative social evaluation no information or information that stressed one of four types of causes: internal/controllable, internal/uncontrollable, external/controllable, and external/uncontrollable. Results indicated that stressing internal/ controllable causes produced more positive affective reactions and performance evaluations among internal locus of control respondents, whereas externals were more variable in their responses. Experiment 2 assessed the generalizability of these findings by administering causal counseling to individuals who identified themselves as interpersonally anxious. Utilizing a quasicounseling design, participants were exposed to one of two interpretations emphasizing internal control or coping. The results of Experiment 2 confirmed initial conclusions that the effectiveness of causal counseling may depend on the individual's locus of control.
\end{abstract}

An attributional approach to social behavior traces problems in personal adjustment back to the assumptions individuals formulate concerning the causes of behaviors and events (Abramson, Seligman, \& Teasdale, 1978; Valins \& Nisbett, 1971). According to this perspective, the person who experiences a stressful life event-such as loss of employment, dissolution of an intimate relationship, or continual family disharmony - will explain this event by making causal inferences that can, in part, determine personal adjustment during and after the life crisis. Research dealing with learned helplessness (e.g., Abramson et al., 1978; Wortman, 1976), self-blame (Brockner \& Hulton, 1978; Janoff-Bulman, 1979), and reactions to failure (Dweck, 1975; Tennen \& Eller, 1977) has documented the relationship between psychological well-being and attributions.

Thanks are extended to Joseph H. Porter, Everett L. Worthington, Jr., and Stanley R. Strong for their help and encouragement during various phases of this project, and to Amy Coberly, Rick Casell, Wendy Ellis, and Phyllis Talley for their assistance as experimenters and/or interviewers.

Requests for reprints should be sent to Nancy L. Forsyth, Department of Psychology, Virginia Commonwealth University, 800 W. Franklin Street, Richmond, Virginia 23284.
Reasoning that personal adjustment is linked to the attributions people make about stressful life events, Altmaier, Leary, Forsyth, and Ansel (1979) suggested that attributional information presented during counseling can have therapeutically beneficial consequences. In their research students who received a harsh personal criticism from another student were given information that indicated this negative event was the result of external, rather than internal, causes. This "causal counseling" helped some of the students cope with the negative evaluation, but the effectiveness of the counseling depended on when the information was given and the locus of control of the subject (Rotter, 1966). When the explanation of the negative event was given immediately after the feedback, externals benefited more than internals. After a delay, however, the external attributional information helped internals more than externals.

Although these findings clearly demonstrate the utility of an attributional approach to counseling, the factors that determine the effectiveness of causal interpretations remain unspecified. Although the content of the treatment information presented in the Altmaier et al. study emphasized subjects' perceptions of the origin of their negative 
evaluation (i.e., either internally or externally caused), perceived controllability should be a second key determinant of the effectiveness of causal counseling. Numerous theories of psychological functioning emphasize the concept of effective control (e.g., Kelly, 1955; deCharms, 1968; White, 1959), and the relevant research indicates that loss of control is associated with depression (Seligman, 1975), motivational deficits (Weiner, 1979), deterioration of physical health (Langer \& Rodin, 1976; Schulz \& Hanusa, 1978), inadequate coping (Bulman \& Wortman, 1977), and stressrelated illnesses (Glass, 1977). Indeed, both Wortman (1976; Wortman \& Dintzer, 1978) and Seligman (1975; Abramson et al., 1978) emphasize controllability in their theories of learned helplessness, and Weiner (1979) has recently revised his attribution theory to include this critical dimension.

The current project examined the relationship between the content of attributional interpretations and the effectiveness of counseling by utilizing both laboratory and quasi-counseling experimentation. In Experiment 1 , theoretically meaningful hypotheses based on an attributional interpretation of treatment settings were subjected to rigorous tests to determine which "attributional messages" help people adjust to negative interpersonal events. Once the effective message was isolated via laboratory experimentation, the attributional approach was further tested in Experiment 2 by exposing individuals reporting problems of social anxiety to differing causal interpretations.

\section{Experiment 1}

As is frequently the case when general theories of human behavior are applied to therapeutic settings, attributional models offer no absolute guidelines specifying the most effective causal interpretation in all counseling settings. However, both Weiner's (1979) and Wortman's (1976; Wortman \& Dintzer, 1978) approaches, when applied to counseling, suggest that the effectiveness of therapy will be greatest when internal, controllable causes are stressed. Although the amount of initial anxiety the client experiences just after a stress-producing life event may be reduced by stressing external, uncontrollable causal factors, subsequent coping and adjustment should be greater when the internal factors that led to the event and the client's responsibility for changing these factors are acknowledged. Just as mastery-oriented children interpret school failures as cues to work harder (Diener \& Dweck, 1978), college students report more positive affective states when they feel they can control their outcomes (Forsyth \& McMillan, 1981a), and rape and accident victims cope more effectively when they attribute their misfortunes to internal, controllable factors (Janoff-Bulman, 1979; Bulman \& Wortman, 1977), adjustment to many types of psychological problems may be facilitated through the formation of internal, controllable attributions (cf. Thompson, 1981).

In order to assess the validity of this analysis, the internality and controllability of the causal factors emphasized in an attributional interpretation were systematically manipulated in Experiment 1. Using procedures developed by Altmaier et al., subjects were exposed to a negative personal evaluation supposedly written by a recent acquaintance. After reading the evaluation subjects were then exposed to interpretations that emphasized an internal or external causal factor that was either controllable or uncontrollable. After listening to this attributional interpretation, subjects' reactions to the experience were assessed to determine which interpretations successfully reduced participants' tendencies to (a) interpret the evaluation in negative, personally threatening terms; (b) evaluate themselves in negative terms; (c) avoid future situations in which evaluations would be received; and (d) generalize from the evaluation received in the experiment to other social situations. A control condition that received the evaluation and completed the dependent measures but was given no treatment was also included.

Although the attributional approach to psychological adjustment predicts that the effectiveness of the interpretation will be greatest when internal controllable causes are stressed, the magnitude of this effect may depend, in part, on the locus of control of the client (Altmaier et al., 1979). Whereas in- 
ternal/controllable interpretations are consistent with internals' locus of reinforcement, externals may reject this information. As Claiborn, Ward, and Strong (1981) recently reported, when counselors interpret their clients' problems in terms that are congruent with the clients' initial beliefs, healthy adjustment becomes more likely. In contrast, incongruent interpretations are less effective. To test this convergence hypothesis in the present study, subjects were classified as either internal or external in their locus of control orientation, and responses to the dependent measures were examined in 2 (internal vs. external locus of control) $\times 2$ (internal vs. external attributional interpretation) $\times 2$ (controllable vs. uncontrollable interpretation) analyses of variance. Given the hypothesized role of locus of control as a mediator of attributional interpretation effectiveness, a three-way interaction was predicted: internals should be more positively influenced by an internal/controllable interpretation, whereas externals should be more positively influenced by interpretations that stress external causes.

\section{Method}

\section{Subjects}

The 58 females and 24 males who participated in the study were volunteers recruited from a larger pool of respondents $(n=205)$ to the Internal-External Locus of Control Scale (Rotter, 1966). More females than males participated simply because of their greater availability in the pool. Subjects were run in same-sex pairs, and three experimenters-two females and one male-ran an equal number of subjects in each condition. Because all subjects were students in introductory psychology classes, care was taken to make sure that pairs were always composed of students from different sections. Furthermore, if either member of a pair indicated that they were acquainted with their partner, the session was terminated (this situation arose only once). All participants were given class credit for participation.

\section{Procedure}

Upon arrival, the two subjects were told that, as participants in a study of impression formation, they would be asked to have a conversation with each other and afterwards complete a short questionnaire. After the subjects agreed to participate by signing a consent form, the experimenter gave them a list of questions to follow during their interaction. This list, which comprised such questions as "What is your major?" and
"What do you plan to do when you get out of school?" was included in order to control the content, direction, and intimacy level of the conversation. The experimenter reminded the subjects that they had about 10 minutes for their talk before exiting. The conversation itself was monitored by the experimenter from the next room.

After 10 minutes the experimenter ended the conversation, separated the subjects into different rooms, and gave each an envelope containing a short questionnaire. This form consisted of six Likert-type items for evaluating their partner in the conversation and included such questions as "How interesting was the conversation?"; "How interesting was the other participant?"; and "Would you like to have another conversation with the other person?" Subjects were left alone to complete their questionnaires, but were asked to return the evaluation to the envelope when finished.

When the evaluations had been completed the experimenter returned to each subject and explained "I am now going to let you see the other person's ratings of you. He(She) didn't know that we were going to give them to you, so the information on the form should be relatively honest." In actuality, the envelopes given the subjects contained bogus questionnaires that had been completed to represent a negative evaluation: The conversation and the subject were rated as uninteresting, the indicated liking for the person was very low, and the respondent had apparently refused to consider having a second conversation with the subject (all responses were either 2 or 3 on the negative pole of the 8-point scales).

When the subjects had had time to look over the bogus forms the experimenter returned and, for all conditions but the control, administered the attributional information. The experimenter told subjects that if they had received a negative evaluation-which sometimes happens in the study - they should try to understand what could have caused this outcome. Subjects were randomly assigned to one of four possible treatments which varied in terms of internality of cause (internal vs. external) and controllability of cause (controllable vs. uncontrollable). For example, in the internal/controllable condition subjects were told:

What we find is that usually when you interact with a person you tend to make a certain kind of impression. Basically, the impression you make-either good or bad-depends upon how you act. Unfortunately, in this study you may not have been able to do the things that lead to good impressions because you couldn't get involved enough in making an impression. People, of course, can always control the impression they make with others by changing their behavior, letting them know things about themselves. However, because you personally couldn't get involved in the interaction you may not have gotten a highly positive evaluation. If this did happen, remember it was becauise of the things you did, but that usually you can control these things better than this.

The external/controllable condition emphasized the importance of situational causes that can be controlled, and ended with the sentence "If this did happen, re- 
member it was because of the situation, but that you can usually control situations better than this." The internal/uncontrollable interpretation emphasized "personality" and ended by stating "Remember it was because of something about your personality, which is something you can't do anything about." Lastly, the external/uncontrollable condition pointed to the "artificiality of the setting" and ended with "remember it was because of the situation, which is something that you can't do anything about." No explanation of the negative evaluation was provided for control condition subjects.

Immediately following the manipulation subjects completed a questionnaire containing the dependent measures. These included (a) two 9-point Likert-type items that checked the effectiveness of the therapy manipulations; (b) one 9-point Likert-type question that measured subjects' perceptions of their evaluations; (c) 147-point semantic differential measures of affect (these items, when used by Forsyth \& McMillan, 1981b, to assess affective reactions to educational outcomes, were found to have an alpha coefficient of .952); (d) a measure of willingness to participate in additional conversations (this item was used by Altmaier et al., 1979, who labeled it a behavioral measure because it implies behavioral commitment); and (e) five 9-point Likert-type scales designed to measure self-ratings of general conversational skills and attractiveness.

Last, subjects were carefully debriefed and thanked for their participation. A serious attempt was made to determine whether any of the participants were doubtful of the authenticity of the situation, and any concerns were fully discussed. As a result, the data for one subject (a male, internal locus of control) were deleted prior to analysis because he expressed extreme suspicion concerning the validity of his evaluation.

\section{Results and Discussion}

Subjects selected for the study had extreme scores on Rotter's (1966) locus of control scale and the personal control subscale identified by Gurin, Gurin, and Morrison (1978; Items $9,12,15,25$, and 28 of the original scale). The locus of control means, 6.9 for internals and 14.5 for externals, were clearly different from one another, $F(1,79)$ $=219.99, p<.05$, as were the personal control means for these same two groups: 2.7 and $4.4, F(1,79)=87.89, p<.05$. The dependent measures were examined using 2 (internal vs. external counseling) $\times 2$ (controllable vs. uncontrollable counseling) $\times 2$ (internal vs. external locus of control) analyses of variance, which, because of the nonorthogonality produced by the unequal cell sizes, relied on least squares regression procedures that adjusted each effect for those of equal or lower order. Initial analyses utilizing gender as a fully crossed factor re- vealed no discernible differences between males' and females' responses. Last, unless otherwise noted, multiple mean comparisons were conducted using Duncan's multiple range test at the .05 level; the error term used in all these tests was based on both experimental and the control subjects' responses (cf. Himmelfarb, 1975).

\section{Manipulation Checks}

Internality. A main effect of internal versus external interpretation on the item "To what extent do you think the evaluation you received from the other person was caused by personal factors versus environmental factors?" $F(1,58)=7.43, p<.05$, indicated that subjects in the internal interpretation condition stressed personal factors over environmental factors more than did the external condition subjects. The respective means were 4.1 and 5.4; the control condition mean was 4.4 and did not differ from either condition. No other effects were significant on this item.

Controllability. The only significant effect on the item "To what extent do you think the evaluation you received from the other person was caused by things you can't ever control versus can always control?" was a main effect of controllability, $F(1,58)=$ $3.91, p=.05$. The controllable interpretation mean was 4.2 and the uncontrollable condition mean was 3.2 , indicating that this manipulation was also effective. The mean for the control condition was 4.3 and did not differ from the controllable condition mean.

\section{Perceptions of Evaluation}

Given the severity of the message, it was assumed that all subjects would accurately perceive their feedback as a negative evaluation. Confirming this expectation, the overall mean on the item "What kind of evaluation did you receive?" was only 1.75 on the "very negative" side of the 9-point scale. However, effects of the attributional interpretations were also in evidence, for analysis revealed a significant three-way interaction of internality, controllability, and locus of control, $F(1,58)=5.71, p<.05$. As 
Table 1

Perceptions of the Evaluation

\begin{tabular}{ccccccc}
\hline \multirow{2}{*}{$\begin{array}{c}\text { Locus } \\
\text { of } \\
\text { control }\end{array}$} & Controllable & Uncontrollable & & Controllable & Uncontrollable & $\begin{array}{c}\text { Control } \\
\text { condition } \\
\text { (no therapy) }\end{array}$ \\
$\begin{array}{c}\text { Internal } \\
M\end{array}$ & $2.75_{\mathrm{a}}$ & $1.45_{\mathrm{b}}$ & & $1.55_{\mathrm{b}}$ & $1.87_{\mathrm{a}, \mathrm{b}}$ & $2.00_{\mathrm{a}}$ \\
$\begin{array}{c}n \\
n\end{array}$ & 8 & 11 & & 9 & 8 & 7 \\
$\begin{array}{c}\text { External } \\
M\end{array}$ & $1.62_{\mathrm{b}}$ & $1.33_{\mathrm{b}}$ & & $1.87_{\mathrm{a}, \mathrm{b}}$ & $1.25_{\mathrm{b}}$ & $1.87_{\mathrm{a}, \mathrm{b}}$ \\
$n$ & 8 & 6 & & 8 & 8 & 8 \\
\hline
\end{tabular}

Note. Higher scores indicate more positive evaluation ratings. Means without a common subscript differ at the, 05 level by Duncan's new multiple-range test.

Table 1 shows, emphasizing internal but controllable causes alleviated some of the harshness of the negative evaluations for internals, but not for externals. Furthermore, if internals were told that their evaluation resulted from internal/uncontrollable causes or external/controllable causes, the evaluation was perceived to be especially aversive-as reflected in the significant differences between these two conditions and the no-interpretation control condition. The simple simple main effect of controllability approached significance for externals, $F(1,58)=3.56, p<.07$, indicating that the uncontrollable interpretations heightened the negativity of the evaluations, but the overall differences between the attributional interpretations were less pronounced than these same differences found for internals.

These findings are consistent with other studies that emphasize the role that attributions play in easing the aversiveness of negative events (Abramson et al., 1978). As Thompson (1981, p. 95) concluded after reviewing a number of studies of control, "cognitive control appears to have uniformly positive effects on the experience of an aversive event," partly because it "reduces the impact of the stimulus." The current findings suggest that for internals, a negative event that is internally controllable is not as aversive as a negative event that is uncontrollable. Control also seemed to benefit externals to some extent, but the magnitude of the effect leaves the question open.

\section{Affective Reactions}

Because it is both conceptually (Osgood,
Suci, \& Tannenbaum, 1957) and statistically (Gorsuch, 1974) advisable to factor analyze semantic differentials when they are used for dependent variable assessment purposes, a principal axes factor analysis was performed on the 14 bipolar adjective measures of affect. This analysis revealed only one major factor that accounted for $79 \%$ of the variance with an eigenvector of 7.14. Items such as incompetent-competent and adequateinadequate loaded highly on this factor (loadings $=.66 \& .88$, respectively), which was interpreted to be a measure of personal competence. ${ }^{1}$

When the standardized factor scores for personal competence were computed and used as the dependent measure in a subsequent analysis of variance, an Internality $x$ Controllability $\times$ Locus of Control interaction was revealed; $F(1,58)=4.02, p<.05$. The factor score means, presented in Table 2 , indicate once more that for internal locus of control subjects, the internal/controllable approach to counseling was the most effective. Respondents in this condition indicated they felt more competent than the subjects in both the internal/uncontrollable counseling condition and the external/controllable counseling condition $(p s<.05)$. These differences, however, held only for internals. Once more no statistically sig-

\footnotetext{
1 So that the factor analysis was not biased by the manipulations used in the investigation, the within-cells correlation matrix (computed by subtracting the appropriate cell mean from each subject's raw score) was used as input into the initial factoring procedure. The average of the item commonalities was quite high (.70), testifying to the internal consistency of the items.
} 
Table 2

Standardized Factor Scores of Personal Competence

\begin{tabular}{|c|c|c|c|c|c|}
\hline \multirow{2}{*}{$\begin{array}{l}\text { Locus } \\
\text { of } \\
\text { control }\end{array}$} & \multicolumn{2}{|c|}{ Internal therapy } & \multicolumn{2}{|c|}{ External therapy } & \multirow{2}{*}{$\begin{array}{l}\text { Control } \\
\text { condition }\end{array}$} \\
\hline & Controllable & Uncontrollable & Controllable & Uncontrollable & \\
\hline $\begin{array}{l}\text { Internal } \\
\text { External }\end{array}$ & $\begin{array}{l}+.356_{\mathrm{a}} \\
-.127_{\mathrm{a}, \mathrm{b}}\end{array}$ & $\begin{array}{l}-.234_{b} \\
+.124_{a, b}\end{array}$ & $\begin{array}{l}-.274_{\mathrm{b}} \\
+.181_{\mathrm{a}, \mathrm{b}}\end{array}$ & $\begin{array}{l}+.090_{\mathrm{a}, \mathrm{b}} \\
+.207_{\mathrm{a}, \mathrm{b}}\end{array}$ & $\begin{array}{l}-.024_{\mathrm{a}, \mathrm{b}} \\
-.150_{\mathrm{a}, \mathrm{b}}\end{array}$ \\
\hline
\end{tabular}

Note. Higher scores indicate more positive evaluation ratings. Means without a common subscript differ at the .05 level by Duncan's new multiple-range test.

nificant differences were found across the counseling conditions for externals.

\section{Behavioral Assessment}

Analysis of subjects' responses to the item "How many more conversations such as the one you had today would you be willing to volunteer for in the future?" revealed a significant interaction of internality and controllability, $F(1,58)=5.08, p<.05$. Subjects checked one of the alternatives, $0-1$, $2-3,4-5$, or 6 or more, and responses were coded from 1 to 4 corresponding to each choice.

As Table 3 shows, when internal causes were emphasized, subjects were willing to come back for an average of 2 to 3 more conversations-about the same number as the no-cause control condition subjects. However, when the therapeutic information suggested situational causes had produced the negative evaluation, subjects volunteered for more conversations only if these causes were described as uncontrollable rather than controllable. Indeed, external/controllable information had the effect of decreasing the amount of volunteering to below the level of the control condition.

Table 3

Responses to Behavioral Assessment

\begin{tabular}{llll}
\hline & \multicolumn{2}{c}{ Internality } & \\
\cline { 2 - 3 } Controllability & Internal & External & Control \\
\hline Controllable & $2.25_{\mathrm{a}, \mathrm{b}}$ & $1.65_{\mathrm{b}}$ & $2.47_{\mathrm{a}}$ \\
Uncontrollable & $2.18_{\mathrm{a}, \mathrm{b}}$ & $2.75_{\mathrm{a}}$ & \\
\hline
\end{tabular}

Note. Means without a common subscript differ at the .05 level by Duncan's new multiple-range test. Higher scores indicate willingness to participate in a greater number of future conversations.

\section{Self-Evaluations}

Responses to the five measures of communication skills, interpersonal attractiveness, and bias in the other's perceptions were analyzed in a 2 (locus of control) $\times 2$ (internality) $\times 2$ (controllability) multivariate analysis of variance that used Pillai's trace as the approximation to $F$ (Pillai, 1965). Because no significant effects were obtained multivariately, no univariate tests were conducted.

\section{Experiment 2}

The fundamental assumption of an attributional approach to therapy - that some of the negative effects of stressful life events can be reduced by helping the client formulate attributions that promote healthy psychological functioning-was supported in Experiment 1 with certain qualifications. First, whereas the theoretically predicted relationship between adjustment and internal controllable attributions held for internals, externals did not respond well to this type of attributional information. Indeed, externals did not show significantly improved postevaluation reactions in any of the experimental conditions. Second, because of the artificiality of the laboratory procedures used in the experiment, the generalizability of these results to therapeutic settings is unknown.

To partially rectify these two problems, a second study was conducted employing an analogue method that more closely approximates an on-going counseling setting. Subjects who identified themselves as socially anxious and desiring help with the problem reported for two interview sessions, spaced a week apart. During these sessions 
interviewers discussed the nature of the subjects' difficulties and made recommendations concerning the causes of this social anxiety. Thus, the quasi-counseling situations were carefully constructed to meet the generalizability requirements specified by Strong: conversation between persons of unequal status; few to many contacts between the individuals; one party is motivated to change; and one party is psychologically distressed and heavily invested in the behaviors that are being discussed (Strong, 1971 , in press).

Based on the results of Experiment 1, two types of therapies were developed. The first approach, labeled internal/controllable counseling, stressed the "client's" ability to personally control social situations and anxiety. In both counseling sessions the interviewer described social anxiety as a controllable nervousness that can be alleviated through practice, determination, and effort. The second approach, labeled coping counseling, was included in an exploratory attempt to discover an interpretation that benefits individuals with an external locus of control. In this condition the interviewer interpreted social anxiety as a nearly unavoidable consequence of social life. The interviewer stressed that everyone is socially anxious but in some people this nervousness is undetectable because they have learned to cope with it.

It was hypothesized that both of the therapies would help participants, as indicated by pretest-posttest changes on selfratings of social anxiety and social competence. Furthermore, effects of locus of control were again anticipated, with internals benefiting more from the internal/controllable counseling and externals benefiting more from the coping counseling. However, because participants were self-referred, there was no opportunity to select only extreme scorers on the Internal-External Locus of Control Scale. Additionally, we were reluctant to exclude people from the project simply because they did not possess an empirically interesting locus of control orientation. Therefore, locus of control was not assessed until the first session of Experiment 2 , and no attempt was made to dichotomize subjects along this measure. Instead, the correlations between locus of control and the effectiveness of attributional interpretations were examined to test the following hypotheses:

Hypothesis 1. The psychological adjustment of participants assigned to the internal/controllable counseling condition should be significantly correlated with locus of control: the more internal the individual, the more effective the internal/controllable treatment.

Hypothesis 2. Adjustment of participants assigned to the coping condition should be significantly correlated, in an inverse direction, with locus of control: the more internal the individual, the less effective the coping treatment (or, the more external the individual, the more effective the coping treatment).

\section{Method}

\section{Subjects}

The 6 males and 18 females who participated responded to a notice posted outside introductory psychology classrooms. The notice invited anyone who felt stressed when interacting with others to participate by attending two interview sessions designed to "look at your anxiety in social situations, to help you understand the source of your feelings better, and to help you deal more effectively with the nervousness you feel." Three females (aged 20,22, and 25 years) conducted equal numbers of sessions across conditions. The interviewers, who were experienced in crisis intervention, stress innoculation training, and intake interviewing, were all extensively trained prior to the first sessions. Training involved the use of videotaped models and practice interview sessions, and uniformity in counseling was ensured by requiring that each interviewer memorize a detailed script. Participants received class credit for participating.

\section{Procedure}

Session 1. After the pretest measures described below were completed, the actual interview began with the interviewer asking the participant to discuss situations that arouse feelings of social anxiety. During the following 20 minutes, subjects were encouraged to talk freely about their problems, with the interviewer facilitating the conversation. During this time, the interviewer would also interject preformulated interpretations appropriate to the subject's randomly assigned experimental condition. In the internal/controllable counseling condition, the interviewer suggested that social anxiety, though stemming from internal factors, was controllable. In the coping counseling condition, the interviewer commented that "lots of us have experienced this sort of problem" but that socially 
skilled persons have learned to cope with this nervousness.

After 20 or 30 minutes of discussion, the interviewer broke the flow of the conversation for a series of interpretations that again depended on the participant's experimental condition. In the internal/controllable condition, these interpretations reiterated the theme that "the key to smooth, enjoyable interactions with others is practicing control of yourself, your anxiety, and your tension." In contrast, the coping interpretations emphasized the idea that "The key to smooth, enjoyable interactions with others is learning how to cope with your nervousness and tension." Following these interpretations, which were given verbatim, subjects were given a list of "homework" assignments. These as signments, included a number of interpersonal tasks, such as taking a friend out for a cup of coffee, asking a salesperson for assistance, or introducing oneself to a stranger at a party, and participants were asked to perform at least three before the next session.

Session 2. The second session followed the same general format as the earlier one. It began with a discussion of the homework assignments and again the interviewer facilitated the conversation by injecting condition-appropriate interpretations. Each session ended with a summary of the attributional interpretation and a debriefing. Any participants who expressed an interest in receiving further help were referred for additional counseling.

Measures. At the beginning and end of the research, participants completed a series of questionnaires. Social anxiety was assessed using three Likert-type items concerned with interpersonal skills, anxiety, and ability to make good impressions. Personal competence was measured on the semantic-differential scales utilized in Experiment 1. Only the pretest measures included Rotter's locus of control scale (1966), and only the posttest measure included manipulation check items.

\section{Results and Discussion}

\section{Perceptions of the Interview Situation}

One-way analyses of variance revealed no differences between subjects in the two experimental conditions (internal/controllable vs. coping therapy) on three items assessing perceptions of interviewers' experience, sensitivity, and helpfulness; the means for these 9-point scales were $8.3,8.4$, and 8.2, indicating that subjects felt that the interviewers were all quite competent. In addition, analyses revealed no differences between the three participating interviewers or differences in the responses of male and female subjects.

A significant effect of condition was obtained, however, on the manipulation check item: "The interviewer suggested you should learn to" with endpoints "develop effective social skills" (1) and "cope with social anxiety" $(9), F(1,21)=7.22, p<.05$. The cope condition mean was significantly higher than the internal/controllable condition mean, indicating that attributional interpretations had been effectively differentiated; the means were 8.1 and 5.1, respectively.

\section{Treatment Effects}

As expected, both the coping and internal/controllable attributional interpretations effectively reduced participants' levels of social anxiety. First of all, a 2 (condition: coping vs. internal/controllable) $\times 2$ (time: pretest and posttest) repeated measures multivariate analysis of variance revealed only a significant effect of time, $F(3,20)=$ $3.73, p<.05$. The univariate results, which are shown in Table 4, indicate that on all three measures subjects reported improvement from the pretest to the posttest. Second, when the personal competence factor score derived from the 14 semantic differentials was examined in a $2 \times 2$ analysis of variance, a main effect of time was also obtained. As shown in Table 4, this finding again indicates that individuals felt more competent after the two sessions than before the sessions.

Although these results suggest that both treatments worked equally well, correlational findings revealed that the attributional interpretations were differentially

Table 4

Change in Self-Ratings of Social Anxiety

\begin{tabular}{lccc}
\hline & \multicolumn{3}{c}{ Time of measurement } \\
\cline { 2 - 3 } \multicolumn{1}{c}{ Measure } & Pretest & Posttest & $F$ \\
\hline Interpersonal skills & 5.83 & 6.58 & $8.20^{*}$ \\
$\begin{array}{l}\text { Social anxiety } \\
\text { Effectiveness in } \\
\quad \text { making a good } \\
\text { impression }\end{array}$ & 5.12 & 4.46 & $5.55^{*}$ \\
Personal competence & 5.67 & 6.42 & $6.19^{*}$ \\
\hline
\end{tabular}

Note. High scores indicate more positive evaluations, except for the social anxiety measure. The $F$ ratio tests the main effect of time of measurement with $d f=1$, 22.

$* p<.05$. 
Table 5

Correlations Between Locus of Control and Self-Ratings of Social Anxiety

\begin{tabular}{|c|c|c|c|c|}
\hline \multirow[b]{2}{*}{ Measure } & \multirow{2}{*}{$\begin{array}{l}\text { Over- } \\
\text { all } \\
r\end{array}$} & \multicolumn{2}{|c|}{$r$ by condition } & \\
\hline & & $\mathrm{I} / \mathrm{C}$ & C & \\
\hline $\begin{array}{l}\text { Interpersonal skills } \\
\text { Social anxiety }\end{array}$ & $\begin{array}{l}+.13 \\
-.14\end{array}$ & $\begin{array}{l}+.57^{*} \\
-.30\end{array}$ & $\begin{array}{l}-.18 \\
-.06\end{array}$ & $\begin{array}{l}1.77^{*} \\
0.79\end{array}$ \\
\hline $\begin{array}{l}\text { Effectiveness in } \\
\text { making a good }\end{array}$ & & & & \\
\hline $\begin{array}{l}\text { Impression } \\
\text { Personal competence }\end{array}$ & $\begin{array}{l}-.12 \\
+.06\end{array}$ & $\begin{array}{l}+.21 \\
+.58^{*}\end{array}$ & $\begin{array}{l}-.39 \\
-.24\end{array}$ & $\begin{array}{l}1.33 \\
3.16^{*}\end{array}$ \\
\hline
\end{tabular}

Note. Higher locus of control scores indicate more internal. $\mathrm{I} / \mathrm{C}=$ internal/controllable therapy, $\mathrm{C}=$ coping therapy. The $z$ ratio tests for differences between the $\mathrm{I} / \mathrm{C}$ and $\mathrm{C}$ condition correlations.

${ }^{*} p<.05$.

effective depending on subjects' locus of control orientations. As shown in Table 5, the correlation between locus of control and the four self-evaluation measures (with the effects of pretest scores partialled out) were nonsignificant. However, this analysis collapses across the two interpretation conditions; when the correlations are recomputed separately for the two treatment conditions, clearer evidence of a relationship is obtained. Supporting Hypothesis 1, in the internal/ controllable condition, locus of control is significantly correlated with positive selfevaluations on two of the four items, and the correlations fall in the predicted direction on the other two items. In other words, as Experiment 1 suggested, the more internal the individual, the more he or she benefited from the internal/controllable treatment. Furthermore, although Hypothesis 2 was not directly supported, since the relationships between locus of control and self-evaluations were not significantly negative in the coping condition, a trend toward the predicted reversal was suggested by the pattern of the correlations. For 2 of the 4 items, the correlation between locus of control and selfevaluations was significantly more negative in the coping condition than in the inter$\mathrm{nal} /$ controllable condition $(p s<.05)$.

\section{Conclusions}

Drawing from both past and present research, attribution theory seems to provide a reasonable framework for interpreting the counseling process. Whereas the exploration of causes through discussion seems to be an inappropriate technique when thought processes, and thus the formulation of attributions, are severely disordered, laboratory (Altmaier et al., 1979), field (Dweck, 1975), and case work (e.g., Johnson, Ross, \& Mastria, 1977) indicate such counseling is successful when used in short-term counseling focused on specific behavioral or emotional problems. For example, Johnson et al. report a successful attributional approach to the treatment of delusional behavior that resulted from anxiety over masturbation, and Dweck helped children deal with "math phobia" by teaching them to attribute their outcomes to factors they could control. Further, Experiment 2 suggests that problems of interpersonal anxiety may be controlled through the use of attributional counseling.

If the effects obtained in this research are representative of those that would be found in on-going counseling, then these results raise several important issues. For example, in both studies internal locus of control subjects reaped greater benefits from the exploration of causes than did externals. In fact, when treatment information that emphasized internal/controllable causal factors was presented to externals, the information had detrimental effects. Thus, although controllability of causes seems to be a critical attribution to emphasize in most situations, these findings suggest that in certain situations with certain types of clients, a therapeutic message that emphasizes an altogether different set of causes may be most effective. For example, the results of Experiment 1 suggest that an emphasis on external, uncontrollable causes may be the most effective approach to take when trying to ensure that a client will repeat behavior that once resulted in a negative outcome. Many situations that an individual might encounter have a high probability of resulting in a negative outcome (e.g., a job interview, meeting new people), but avoidance of these situations might be more detrimental to the client's psychological functioning than further negative experiences. Therefore, if reliance on external, controllable causal outlook will increase the chance 
of repetition of the behavior, this type of attribution may be the most appropriate to the situation. Both experiments suggest that discussing causes is helpful, but neither purports to demonstrate that certain attributions are always better than others.

A related question left unanswered by this research concerns the function of attributions in maintaining psychological wellbeing. Although early analyses of attribution conceptualized this process as a logical search for causes of actions and events, subsequent work has repeatedly demonstrated that attributions are more often than not biased by desires to reduce feelings of incompetency, insecurity, guilt, or embarrassment (Forsyth, 1980; Greenwald, 1980). Yet, if it is "normal" for people to externalize their failures, to think that they control outcomes when they don't, to perceive contingencies where none exist, and to feel comforted when arousal is misattributed to unrelated but alterable causal factors, the following question arises: Should counselors help their clients regain a "normal" state of mild attributional egocentrism?

For example, in Experiment 1 subjects who responded most positively to the aversive evaluation (internal locus of control receiving an internal/controllable interpretation) felt their evaluations were slightly more positive than did the other respondents. However, their reinterpretation of the evaluation in more positive terms was not an irrational denial of their outcomes; they realized they had apparently made a poor impression. Rather, the attributional interpretation softened the blow of an unexpectedly harsh experience by providing a psychologically feasible explanation for the event. An attributional approach to counseling emphasizes the interpretation of stressful life events in causal terms that promote successful psychological adjustment. Although, of course, these interpretations should be valid in the sense that they accurately reflect the "true" causes of feelings, behaviors, and events, the complexity of most situations allows a choice between causal explanations that are self-protective and those that are self-damaging. The current research suggests that in situations involving multiple causes of complex events, causal interpretations that promote psy- chological well-being are preferable to those that are self-damaging.

To close on a methodological note, the current project illustrates the advantages of integrating laboratory and "real-world" experimentation in the study of psychological adjustment. Although arguments against the utility of laboratory research in generating answers to issues of interest to counselors have been raised (cf. Gelso, 1979; Osipow, Walsh, \& Tosi, 1980), the relatively artificial design of Experiment 1 proved useful in lending support to some of the theoretical underpinnings of the more realistic Experiment 2. Although researchers should certainly exercise caution when attempting to generalize from basic research conducted in highly controlled settings to nonlaboratory situations, such studies can nonetheless be quite relevant to the therapeutic process. Counseling involves complicated, multifaceted phenomena, and psychologists who hope to unravel its many mysteries should be willing to use all their scientific tools-theory construction, insistence on empirical confirmation of hypotheses, replication, and checks for generalizability-in pursuit of more comprehensive understanding.

\section{References}

Abramson, L. Y, Seligman, M. E. P., \& Teasdale, J. D. Learned helplessness in humans: Critique and reformulation. Journal of Abnormal Psychology, $1978,87,49-74$.

Altmaier, E. M., Leary, M. R., Forsyth, D. R., \& Ansel, J. C. Attribution therapy: Effects of locus of control and timing of treatment. Journal of Counseling Psychology, 1979, 26, 481-486.

Brockner, J., \& Hulton, A. J. B. How to reverse the vicious cycle of low self-esteem: The importance of attentional focus. Journal of Experimental Social Psychology, 1978, 14, 564-578.

Bulman, R. J., \& Wortman, C. B. Attributions of blame and coping in the "real world": Severe accident victims react to their lot. Journal of Personality and Social Psychology, 1977, 35, 351-363.

Claiborn, C. D., Ward, S. R., \& Strong, S. R. Effects of congruence between counselor interpretations and client beliefs. Journal of Counseling Psychology, 1981, 28, 101-109.

deCharms, R. Personal causation. New York: Academic Press, 1968.

Diener, C. I., \& Dweck, C. S. An analysis of learned helplessness: Continuous changes in performance, strategy, and achievement cognitions following failure. Journal of Personality and Social Psychology, $1978,36,451-462$. 
Dweck, C.S. The role of expectations and attributions in the alleviation of learned helplessness. Journal of Personality and Social Psychology, 1975, 23, $109-116$.

Forsyth, D. R. The functions of attributions. Social Psychology Quarterly, 1980, 43, 184-189.

Forsyth, D. R., \& McMillan, J. H. Attributions, affect, and expectations: A test of Weiner's three dimensional model. Journal of Educational Psychology, $1981,73,393-401$. (a)

Forsyth, D. R., \& McMillan, J. H. The attribution cube and reactions to educational outcomes. Journal of Educational Psychology, 1981, 73, 632-641. (b)

Gelso, C.J. Research in counseling: Methodological and professional issues. The Counseling Psychologist, 1979, 8, 7-36.

Glass, D. C. Behavior patterns, stress, and coronary disease. Hillsdale, N.J.: Erlbaum, 1977.

Gorsuch, R. L, Factor analysis. Philadelphia: Saunders, 1974.

Greenwald, A. G. The totalitarian ego: Fabrication and revision of personal history. American Psychologist, 1980, 35, 603-618.

Gurin, R., Gurin, G., \& Morrison, B. M. Personal ideological aspects of internal and external control. Social Psychology, 1978, 41, 275-296.

Himmelfarb, S. What do you do when the control group doesn't fit into the factorial design? Psychological Bulletin, 1975, 82, 363-368.

Janoff-Bulman, R. Characterological versus behavior self blame: Inquiries into depression and rape. Journal of Personality and Social Psychology, 1979, 37, 1798-1809.

Johnson, W. G., Ross, J. M., \& Mastria, M. A. Delusional behavior: An attributional analysis of development and modification. Journal of Abnormal Psychology, 1977, 86, 421-426.

Kelly, G. A. The psychology of personal constructs. New York: Norton, 1955.

Langer, E. J., \& Rodin, J. The effects of choice and enhanced personal responsibility for the aged: A field experiment in an institutional setting. Journal of Personality and Social Psychology, 1976, 34, 191-198.

Osgood, C. E., Suci, G. J., \& Tannenbaum, P. H. The measurement of meaning. Urbana, Ill.; University of Illinois Press, 1957.

Osipow, S. H., Walsh, W. B., \& Tosi, D. J. A survey of counseling methods. Homewood, Ill.: Dorsey Press,
1980.

Pillai, K. C. S. On the distribution of the largest characteristics root of a matrix in multivariate analysis. Biometrika , 1965, 52, 405-414.

Rotter, J. B. Generalized expectancies for internal versus external control of reinforcement. Psychological Monographs, 1966, 80(1, Whole No. 609).

Schulz, R., \& Hanusa, B. H. Long-term effects of control and predictability-enhancing interventions: Findings and ethical issues. Journal of Personality and Social Psychology, 1978, 36, 1194-1201.

Seligman, M. E. P. Helplessness: On depression, development and death. San Francisco: Freeman, 1975.

Strong, S. R. Experimental laboratory research in counseling. Journal of Counseling Psychology, 1971, $18,106-110$.

Strong, S. R. Emerging integrations of clinical and social psychology: A clinician's perspective. In G. Weary \& H. Mirels (Eds.), Integrations of clinical and social psychology. Oxford: Oxford University Press, in press.

Tennen, H., \& Eller, S. J. Attributional components of learned helplessness and facilitation. Journal of Personality and Social Psychology, 1977, 35, 265-271.

Thompson, S. C. Will it hurt less if I can control it? A complex answer to a simple question. Psychological Bulletin, 1981, 90, 89-101.

Valins, S., \& Nisbett, R. E. Attribution-process in the development and treatment of emotional disorders. Morristown, N.J.: General Learning Press, 1971.

Weiner, B. A theory of motivation for some classroom experiences. Journal of Educational Psychology, $1979,71,3-25$.

White, R. W. Motivation reconsidered: The concept of competence. Psychological Review, 1959, 66, 297-333.

Wortman, C. B. Causal attributions and personal control. In J. H. Harvey, W. J. Ickes, \& R. F. Kidd (Eds.), New directions in attribution research. Hillsdale, N.J.: Erlbaum, 1976.

Wortman, C. B., \& Dintzer, L. Is an attributional analysis of the learned helplessness phenomenon viable? A critique of the Abramson-SeligmanTeasdale reformulation. Journal of Abnormal Psychology, 1978, 87, 75 90.

Received May 21, 1981 